\title{
SIFAT FISIK DAN MEKANIK KAYU SALAM (Syzygium polyanthum (Wight)Walp.) BERDASARKAN POSISI KETINGGIAN PADA BATANG
}

\author{
(Physical and Mechanical Properties of Salam Wood (Syzygium polyanthum (Wight)Walp.) \\ Based of Height On The Stem)
}

\author{
Erma, Fadillah H. Usman, Muflihati \\ Fakultas Kehutanan Universitas Tanjungpura Pontianak, Jl. Daya Nasional Pontianak 78124 \\ E-mail : ermafahutan12@gmail.com
}

\begin{abstract}
Physical and mechanical properties of wood is one of the basic properties that need to be known in the selection of wood, because the physical and mechanical properties of wood are not the same height on the stem. Increased wood demand gives the opportunity to use wood that is not yet known for its marketing, one of which is Salam wood (Syzygium polianthum (Wight) Walp). The purpose of this research was to determine the physical and mechanical properties of Salam wood based on the height of the stem so that Salam wood can be optimally utilized by testing based on Classification SNI - 5 PKKI 1961. Methods of making test and test examples based on British Standard Methods No. 373-1957. The results showed that Salam wood has physical properties with an average brown colour, the moisture content 3,13\%, density 0,58 $\mathrm{kg} / \mathrm{cm}^{2}$, Depreciation 2,59\%. Salam has mechanical properties with an average height position stem from base to tip with Modulus of Elastiscity (MOE) 97.701,54, Modulus of Rupture (MOR) 659,18 and Modulus Crushing Streang 342,86. Salam can be classified into strong class III and based on its properties and mechanics, it is suitable for use as a lightweight construction and furniture.
\end{abstract}

Keywords: Density, depreciation, MCS, MOE, moisture content, MOR

\section{PENDAHULUAN}

Banyaknya jenis kayu yang tumbuh di Indonesia, tetap saja masyarakat cenderung menggunakan kayu-kayu yang sudah dikenal. Hal ini, dikarenakan penyebaran informasi dan penggunaan kayu-kayu yang belum dikenal masih sebatas tulisan. Selain itu, ketergantungan konsumen terhadap kayu-kayu komersil juga masih sangat tinggi, sehingga kayukayu yang belum diketahui penggunaannya cenderung diabaikan dalam pemanfaatannya. Salah satu jenis kayu yang belum digunakan secara luas adalah kayu Salam (Syzygium polyanthum (Wight)Walp.).
Sifat fisik dan mekanik yang mempunyai prospek cukup baik dimasa yang akan datang. Oleh karena itu, maka perlu dilakukan penelitian sifat fisik dan mekanik kayu Salam berdasarkan posisi ketinggian pada batang. Shmulsky dan Jones (2011) menyebutkan bahwa salah satu cara untuk mengetahui kekuatan kayu adalah dengan mengukur kekuatan lengkung statis kayu. Shmulsky dan Jones (2011) menjelaskan bahwa dalam pengujian kekuatan lengkug statis kayu ada dua parameter yang diukur, yaitu Modulus of Elastiscity (MOE), Modulus Of Rupture (MOR) dan Maximum Crushing Strength (MCS). Hasil penelitian 
akan memberikan informasi tentang kayu Salam sebagai penambah jenis kayu-kayu yang sudah ada sebelumnya di dunia perdagangan dan dapat dimanfaatkan secara optimal.

\section{METODE PENELITIAN}

Penelitian ini di laksanakan di Laboratorium Wood Workshop, Laboratorium Pengolahan Kayu Fakultas Kehutanan, dan Laboratorium Pengujian Bahan dan Metrologi, Politeknik Negeri Pontianak. Pengujian dilakukan berdasarkan British Standar Methods No 373-1957. Ukuran contoh uji untuk kadar air dan kerapatan $2,5 \mathrm{~cm} \times 2,5 \mathrm{~cm} \times 2,5 \mathrm{~cm}$, penyusutan $10 \mathrm{~cm} \times 2,5 \mathrm{~cm} \times 2,5 \mathrm{~cm}, \mathrm{MOE}$ dan MOR $30 \mathrm{~cm}$ x $2,5 \mathrm{~cm}$ x $2,5 \mathrm{~cm}$ dan MCS $6 \mathrm{~cm} \times 2,5 \mathrm{~cm} \times 2,5 \mathrm{~cm}$. Rancangan yang digunakan dalam penelitian ini menggunakan Rancangan Acak Lengkap (RAL) berdasarkan posisi ketinggian pada batang (pangkal, tengah, ujung) dengan 3 kali ulangan.

\section{HASIL DAN PEMBAHASAN}

\section{Sifat Fisik Kayu Salam}

Hasil pengujian warna kayu berdasarkan ketinggian pada batang menunjukan bahwa Warna kayu Salam jika disesuaikan menggunakan Munsell Soil Color Chat (2009) kayu Salam pada bagian pangkal, tengah dan ujung menunjukan warna brown. Warna tersebut tidak mengalami perubahan pada nilai warna, namun ada perbedaan pada kecerahan kayu, dimana bagian ujung lebih cerah dibanding bagian tengah dan pangkal. Sifat warna tersebut dipengaruhi oleh perbedaan lingkungan dan letak pada batang, sebagaimana penelitian sebelumnya oleh Moya dan Berrocal (2010). Ganis Lukmandaru mengidentifikasi warna kayu juga di sebabkan oleh zat ekstraktif yang terkandung pada batang (2009). Nilai ratarata hasil pengukuran sifat fisik kayu sama-sama dapat dilihat pada Tabel 1 berikut ini :

Tabel 1. Rerata sifat Fisik Kayu Salam (Syzygium polyanthum (Wight) Walp.) Berdasarkan Posisi Ketinggian Pada Batang (Average Physical Properties Of Salam Wood (Syzygium polyanthum (Wight) Walp.)Based Of Height On The Stem)

\begin{tabular}{clcc}
\hline No & Sifat Fisik & Satuan & Rata- Rata \\
\hline 1 & Kadar Air & $(\%)$ & 3,13 \\
2 & Kerapatan & $\left(\mathrm{kg} / \mathrm{cm}^{2}\right)$ & 0,58 \\
3 & Penyusutan & $(\%)$ & 2,59 \\
\hline
\end{tabular}

Hasil pengukuran sifat fisik kayu Salam pada Tabel 1, diketahui bahwa kadar air kayu Salam rata-rata 3,13 (\%), Kerapatan $0,58 \quad\left(\mathrm{~kg} / \mathrm{cm}^{2}\right) \quad$ dan
Penyusutan $\quad 2,59 \quad(\%)$ Untuk mengetahui pengaruh posisi ketinggian pada batang dapat dilihat pada Tabel 2 . 
Tabel 2. Pengaruh Sifat Fisik Kayu Salam (Syzygium polyanthum (Wight) Walp.)Berdasarkan Ketinggian Pada Batang (The Influence Physical Properties Of Salam Wood (Syzygium polyanthum (Wight) Walp.) Based Of Height On The Stem)

\begin{tabular}{clcccc}
\hline \multirow{2}{*}{ No } & \multirow{2}{*}{ Sifat Fisik } & \multirow{2}{*}{ Satuan } & \multicolumn{3}{c}{ Ketinggian pada Batang } \\
\cline { 4 - 6 } & & & Pangkal & Tengah & Ujung \\
\hline 1 & Kadar Air & $(\%)$ & 3,23 & 3,18 & 2,98 \\
2 & Kerapatan & $\left(\mathrm{kg} / \mathrm{cm}^{2}\right)$ & 0,61 & 0,59 & 0,54 \\
3 & Penyusutan & $(\%)$ & $\underline{3,17}$ & 2,46 & 2,13 \\
\hline
\end{tabular}

Keterangan : Nilai yang dalam kolom yang dihubungkan oleh garis bawah tidak berbeda nyata

Nilai rerata-rata sifak fisik kayu daun salam paling tinggi berada pada bagian pangkal dan terendah pada bagian ujung (Tabel 2). Hasil analisis keragaman letak posisi ketinggian pada batang tidak berpengaruh terhadap kadar air. Hasil perhitungan kadar air kayu Salam (Syzygium polyanthum (Wight,) Walp,), dilihat dari hasil perhitungan nilai kadar air ketinggian pada batang terjadi penurunan dari pangkal sampai bagian ujung, hal ini dikarenakan pada bagian pangkal selain lebih dekat dengan akar secara struktur anatomi, juga mempunyai susunan sel yang lebih padat sehingga membuat air dalam kayu menjadi cenderung lebih tinggi. Hal ini sesuai dengan Brown. et. al. (1952), yang mengemukakan bahwa kadar air dipengaruhi oleh letak ketinggian kayu dalam batang, struktur anatomi, dan tempat tumbuh.

Pengujian kerapatan menunjukan bahwa posisi ketinggian batang tidak berpengaruh nyata terhadap kayu Salam. Jika dilihat hasil perhitungan nilai kerapatan berdasarkan ketinggian pada batang terjadi penurunan dari pangkal sampai bagian ujung. Hal ini diperkirakan karena adanya perbedaan struktur anatomi kayu, dimana pada bagian pangkal didominasi oleh sel - sel yang telah mengalami penebalan sekunder sehingga dinding selnya cenderung lebih tebal. Seperti yang dikemukakan oleh Haygreen dan Bowyer (1989), kerapatan dipengaruhi oleh strukur anatomi kayu khususnya ketebalan dinding sel sebagaimana dikemukakan oleh Panshin and de Zeeuw (1980) bahwa secara umum tebal dinding sel pada kayu awal bertambah 15\% dari bagian tengah ke luar.

Pengujian penyusutan hasil analisis keragaman letak ketinggian batang berpengaruh sangat nyata terhadap penyusutan. Jika dilihat hasil perhitungan nilai penyusutan ketinggian pada batang terjadi penurunan dari pangkal sampai bagian ujung Perbedaan nilai kerapatan karena disebabkan perbedaan posisi ketinggian pada batang. Hal ini sesuai dengan pendapat Panshin dan De Zeew (1980), bahwa semakin tinggi kerapatan maka akan semakin tinggi pula perubahan dimensi yang terjadi. Hal tersebut menunjukan bahwa dalam pemanfaatannya dapat diambil pada bagian pangkal, tengah dan ujung.

\section{Sifat Mekanik Kayu Salam}

Pengujian sifat mekanik kayu Salam dilakukan pada kayu dalam kondisi kering udara diperoleh data nilai rata-rata hasil pengujian seperti pada Tabel 3. 
Tabel 3. Rerata sifat Mekanik Kayu Salam (Syzygium polyanthum (Wight) Walp.)

Berdasarkan Posisi Ketinggian Pada Batang (Average Mechanical

Properties Of Salam Wood (Syzygium polyanthum (Wight) Walp.)Based Of

Height On The Stem)

\begin{tabular}{clcc}
\hline No & Sifat Mekanik & Satuan & Rata- Rata \\
\hline 1 & Keteguhan lentur statis & $\left(\mathrm{kg} / \mathrm{cm}^{2}\right)$ & $97.701,54$ \\
2 & Keteguhan patah & $\left(\mathrm{kg} / \mathrm{cm}^{2}\right)$ & 659,18 \\
3 & Keteguhan tekan & $\left(\mathrm{kg} / \mathrm{cm}^{2}\right)$ & 342,86 \\
\hline
\end{tabular}

Sifat mekanik yang diuji meliputi sifat keteguhan elastis, keteguhan patah dan keteguhan tekan. Pada umumnya klasifikasi kekuatan kayu di Indonesia didasarkan pada keteguhan lentur pada batas patah dan keteguhan tekan sejajar serat sudah mewakili hubungannya dengan pengolahan dan pemanfaatan kayu untuk keperluan tertentu. Berdasarkan nilai rerata sifat mekanik kayu Salam. Nilai rerata sifat mekanik pada Tabel 3 menunjukkan bahwa kayu Salam tergolong kelas kuat III (NI - 5 PKKI (1961). Namun berdasarkan analisis keragaman menunjukkan bahwa posisi ketinggian batang tidak berpengaruh terhadap sifaf mekanik kayu Salam yang disajikan pada Tabel 4.

Tabel 4. Pengaruh Sifat Mekanik Kayu Salam (Syzygium polyanthum (Wight) Walp.)Berdasarkan Ketinggian Pada Batang (The Influence Mechanical Properties Of Salam Wood (Syzygium polyanthum (Wight) Walp.) Based of Height On The Stem)

\begin{tabular}{cccccc}
\hline \multirow{2}{*}{ No } & \multirow{2}{*}{ Sifat Mekanik } & \multirow{2}{*}{ Satuan } & \multicolumn{3}{c}{ Ketinggian pada Batang } \\
\cline { 4 - 6 } & & & Pangkal & Tengah & Ujung \\
\hline 1 & Keteguhan lentur statis & $\left(\mathrm{kg} / \mathrm{cm}^{2}\right)$ & $101.571,21$ & $97.233,93$ & $97.745,09$ \\
2 & Keteguhan patah & $\left(\mathrm{kg} / \mathrm{cm}^{2}\right)$ & 702,50 & 668,96 & 606,08 \\
3 & Keteguhan tekan & $\left(\mathrm{kg} / \mathrm{cm}^{2}\right)$ & 362,79 & 340,32 & 323,21 \\
\hline
\end{tabular}

Keterangan : Nilai yang dalam kolom yang dihubungkan oleh garis bawah tidak berbeda nyata

Besarnya nilai rerata keteguhan elastis kayu Salam terjadi penurunan dari bagian pangkal ke ujung. Pengaruh keadaan tersebut disebabkan karena faktor arah longitudinal dalam batang atau umur sel dan jaringan dalam bagian batang tersebut, sehingga kekuatan jaringan kayu pada bagian pangkal umumnya lebih tinggi daripada jaringan di bagian ujung batang. Hal tersebut dapat dipengaruhi oleh banyak faktor. Wahyu (2008) menyebutkan bahwa faktor-faktor alam seperti tempat tumbuh, umur, jenis kayu, letak dalam batang, dan diameter akan mempengaruhi sifat fisik maupun sifat mekanik kayu.

Hasil pengujian keteguhan patah nilai MOR terjadi penurunan dari bagian pangkal ke ujung. Sri Nugroho, dkk (2014) menyatakan adanya interaksi antara tempat tumbuh, ketinggian dan arah radial terhadap kadar air dan kerapatannya. Hal ini disebabkan oleh adanya perbedaan nilai kadar air dan kerapatan posisi 
ketinggian pada batang. Kadar air berhubungan langsung dengan kekuatan kayu dalam hal ini semakin tinggi kandungan kadar airnya maka kayu tersebut akan semakin berat dan basah sehingga akan mengakibatkan kayu tersebut lebih rendah untuk dipatahkan (kayunya kurang kuat), seperti yang dikemukakan oleh Haygreen dan Bowyer bahwa kadar air dapat menentukan sifat fisika kayu yang lain seperti kerapatan, kekuatan kayu, keteguhan patah dan keteguhan lengkung statis kayu tersebut. Besar kecilnya keteguhan patah kayu dapat dilihat dari hasil patahan kayu yang diuji, dimana dengan semakin kecil keteguhan patahnya maka kayu akan langsung patah.

Nilai rerata keteguhan tekan nilai (MCS) terjadi penurunan dari bagian pangkal ke ujung. Hal ini diduga bahwa keteguhan tekan dipengaruhi oleh kerapatan kayu. Pada Tabel 1, terlihat nilai rerata kerapatan kayu menurun dari pangkal ke ujung. Semakin tinggi nilai kerapatan kayu maka semakin tinggi pula nilai keteguhan tekannya. Menurut Supraptono (1988), menyatakan bahwa, perbedaan posisi ketinggian batang disebabkan oleh struktur anatominya berupa ukuran sel dan dinding sel dimana pada bagian pangkal lebih tebal dari bagian ujung, sehingga kerapatan bagian pangkal lebih tinggi dari pada bagian tengah dan ujung, dimana keteguhan tekan berbanding lurus dengan kerapatannya.

\section{Kualitas Kayu salam}

Penggunaan kayu sebagai bahan bagunan biasanya diklasifikasikan kedalam beberapa kelas kuat kayu, yang didasarkan pada kerapatan, kuat lentur mutlak dan kuat tekan mutlak. Kelas kuat kayu dapat diketahui berdasarkan Klasifikasi NI - 5 PKKI (1961) dan dibandingkan dengan data hasil pengujian kayu. Pada Tabel 5 tersebut dapat disimpulkan bahwa kualitas kayu Salam dari pangkal ke ujung termasuk kategori berkualitas sedang, dan dapat digunakan untuk konstruksi ringan.

Tabel 5. Rekapitulasi Hasil Penelitian Sifat Mekanik Kayu Salam Berdasarkan Klasifikasi NI - 5 PKKI 1961. (Recapitulation Result Of The Mechanical Properties Salam Wood Based On Clasification NI - 5 PKKI 1961)

\begin{tabular}{clcc}
\hline Parameter & \multicolumn{1}{c}{ Hasil penelitian } & $\begin{array}{c}\text { Klasifikasi } \\
\text { NI - 5 PKKI 1961 }\end{array}$ & $\begin{array}{c}\text { Kelas Kuat Kayu } \\
\text { Berdasarkan Penelitian }\end{array}$ \\
\hline \multirow{2}{*}{ Keteguhan Elastis } & $\begin{array}{l}\text { Pangkal }=110.571,21 \\
\text { Tengah }=97.233,93\end{array}$ & $>$ III \\
& $\begin{array}{l}\text { Ujung }=95,745,09 \\
\text { Pangkal }=702,50\end{array}$ & \\
Keteguhan Patah & $\begin{array}{l}\text { Tengah }=668,96 \\
\text { Ujung }=606,08\end{array}$ & III \\
& $\begin{array}{l}\text { Pangkal }=362,79 \\
\text { keteguhan Tekan } \\
\text { Tengah }=340,32\end{array}$ & & \\
& Ujung $=323,21$ & $425-300$ & III \\
\hline
\end{tabular}




\section{Kesimpulan}

Hasil penelitian tentang Sifat Fisik dan Mekanik Kayu Salam (Syzygium polyanthum (Wight.) Wal.,) Berdasarkan Ketinggian Pada Batang, dapat disimpulkan sebagai berikut :

1. Warna kayu pada bagian pangkal, tengah dan ujung berwarna brown, namun terdapat perbedaan kecerahannya, dimana bagian ujung lebih cerah dibanding bagian tengah dan pangkal. Selanjutnya posisi ketinggian batang tidak berpengaruh terhadap kadar air dan kerapatan dimana nilainya terjadi penurunan pada bagian pangkal ke ujung, Sedangkan penyusutan menunjukkan pengaruh yang sangat nyata terhadap posisi ketinggian pada batang, dan nilainya cenderung menurun pada bagian pangkal ke ujung.

2. Sifat mekanik berdasarkan letak ketinggian pada batang tidak berpengaruh terhadap keteguhan statis, keteguhan patah dan keteguhan tekan namun terjadi penurunan dari bagian pangkal ke bagian ujung.

3. Berdasarkan hasil penelitian yang dibandingkan dengan klasifikasi NI 5 PKKI 1961 bahwa kayu Salam umumnya masuk kedalam kelas kuat III, sehingga hanya dapat dipergunakan untuk kontruksi ringan yang terlindung berada di bawah atap dan tidak berhubungan dengan tanah basah.

\section{Saran}

1. Hasil penelitian diketahui bahwa dari bagian pangkal sampai ujung memiliki sifat fisik dan mekanik terbaik yang termasuk kedalam kelas III, sehingga dapat digunakan sebagai kontruksi ringan dan mebel.

2. Untuk memaksimalkan penggunaan dan pengolahan kayu Salam maka perlu dilakukan penelitian lebih lanjut tentang sifat dasar kayu yaitu mekanik kayu, dengan perlakuan yang lebih beragam, yaitu tidak hanya berdasarkan pada posisi ketinggian batang.

\section{DAFTAR PUSTAKA}

British Standard Institute. 1957. British Standard (BS) 373:1957. Methods of Testing Small Clear Specimens of Timber. British Standard Institution, London. $22 \mathrm{p}$

Brown, H. P. A. J Panshin and C.C. Forsaith.1952. Textbook of Wood Technologi. Vol. II. Mc Graw Hill Book Company. New York. USA.

Haygreen, J.G. dan J.L. Bowyer, 1989. Hasil Hutan dan Ilmu Кауи. Diterjemahkan oleh SutjiptoA. Hadikusumo. UGM-Press. Yogyakarta.

Lukmandaru, Ganis.2009.Pengukuran Kadar Ekstraktif dan Sifat Warna pada Kayu Teras Jati Doreng

(Tektona Grandis).Fakultas Kehutanan UGM. Yogyakarta.

Marsoem, Sri Nugroho.dkk.2014.Studi Mutu Kayu Jati di Hutan Rakyat Gunung kidul.Fakultas Kehutanan UGM, Gunungkidul.

Moya, R, Berrocal, A. (2010). Wood Colour \& variation in sapwood 
and heartwood of young trees of Tectona grandis and its relationship with plantation characteristics, site, and decay resistance. Annals of Forest Science, 67, 109.

Panshin, A. J. and C. de Zeewu.1980. Textbooxof wood Techmology. $4^{\text {th }}$ edition. McGraw-Hill Book Co. New York.

[PKKI] Peraturan Konstruksi Kayu Indonesia. 1961. PKKI NI - 5 1961. Direktorat Jenderal Cipta Karya Departemen Pekerjaan Umum, Bandung.
Shmulsky, R dan P. D. Jones, 2011, Forest Products and Wood Science, An Introduction, Sixth Ed., Wiley

Supraptono, B. 1988. Diktat Mekanika Kayu. Yayasan Pembina.Fakultas Kehutanan Jurusan Teknologi Hasil Hutan UNMUL.Samarinda.

Wahyu, D dan Nugroho, M. 2008. Tinjauan Hasil-hasilpenelitian faktor-faktor alam yang mempengaruhi sifat fisik dan mekanik kayu lndonesia. Jurnal Ilmu dan Teknologi Kayu Tropis. Masyarakat Peneliti Kayu Indonesia. Vol.5(1):8510 